\title{
Dinâmica de Perícia em Local de Crime na Disciplina de Odontologia Forense da FO-USP
}

\author{
Thiago Leite Beaini*, Alice Aquino Zanin, Geraldo Elias Miranda, \\ Marta Flores, Janaina Paiva Curi, Rodolfo F. H. Melani \\ Laboratório de Antropologia e Odontologia Forense \\ Faculdade de Odontologia da Universidade de São Paulo
}

* Autor para correspondência: tbeaini@gmail.com

\begin{abstract}
RESUMO
Na disciplina de Odontologia Forense da Faculdade de Odontologia da Universidade de São Paulo (FO-USP), um modelo de ensino construtivista, que se vale de práticas de dinâmica de grupo e de estudo de caso, busca reunir conhecimentos adquiridos na disciplina e em outras matérias que compõem o currículo da graduação em odontologia. Após uma aula expositiva e leitura prévia de uma apostila no ambiente virtual de aprendizagem, os alunos são divididos em equipes e realizam uma dinâmica de "local de crime", que consiste em observar, descrever, registrar e emitir um relatório estruturado, fatores que se assemelham com o cotidiano clínico do cirurgião-dentista. Atualmente, um número crescente de profissionais vem demonstrando interesse nas carreiras forenses, e a disciplina tem por objetivo preparar o aluno para esse campo de trabalho multidisciplinar. Este relato visa a demonstrar as técnicas utilizadas e os resultados obtidos nos últimos anos com a aula prática pericial em ambiente de graduação.
\end{abstract}

Palavras-chave: Odontologia; Odontologia Legal; Metodologia de Ensino.

\begin{abstract}
The discipline of Forensic Dentistry of the University of São Paulo, a constructive teaching model with group dynamics and case studies that apply previously discussed knowledge and information from other topics from the graduation curriculum. After an expository lecture and previous text reading of the online support content, the students are divided in teams to fulfill a "crime scene investigation" that consists on observation, description, registering and structured reporting the facts, which resembles the daily practice of a Dental Surgeon. Nowadays, there is a raising number of dentists with interest on the forensic careers and the classes have the objective to prepare the student to this field and this multidisciplinary task. This report has the objective of presenting the techniques and the results of the past years with a forensic practice in the undergraduate environment.
\end{abstract}

Keywords: Dentistry; Forensic Dentistry; Teaching Methods.

\section{Introdução}

O ensino é um desafio para todo professor que busca maneiras de fazer com que os alunos aprendam e transformem a realidade. As dinâmicas em grupo e estudos de casos são atividades importantes no processo de conhecimento "porque não somos capazes de aprender isolados da realidade" (GOMES \& POZZEBON, 1989, p. 129).

O trabalho em grupo tem sido uma prática utilizada no modelo de ensino construtivista, pois o conhecimento é construído coletivamente (SCHUNK, 2011). Nessa sistemática o aluno, ao mesmo tempo em que estuda a matéria, aprende a escolher, a avaliar, a decidir, a respeitar as diferenças e as opiniões dos outros colegas para, assim, chegar a um consenso (BARRON, 2000). Tal prática revela-se difícil de ser aplicada na Odontologia por esta ser uma profissão marcada tradicionalmente pelo trabalho individual. Porém, considera-se o trabalho em equipe como um meio de auxiliar o aluno a respeitar as diversidades, fazendo-o confrontar opiniões com vistas a obter um resultado comum.

Na disciplina de Odontologia Forense da FO-USP, por meio do trabalho em grupo é realizado 
o estudo de caso, na forma de simulação, que tem por objetivo desenvolver nos estudantes a capacidade de análise de uma situação concreta e de síntese dos conhecimentos aprendidos (GOMES \& POZZEBON, 1989). Nesse processo, ocorre a valorização do saber experiencial, com ênfase no papel do aluno na geração do conhecimento (ANDRÉ, 1984), pois, a partir da análise do "local de crime" simulado, os alunos deverão argumentar e tomar decisões baseados nas evidências do caso.

A escolha da inserção dessa temática de aula no conteúdo programático da disciplina ocorreu após a constatação do crescente número de cirurgiões-dentistas que ingressam nas carreiras forenses como peritos criminais. Outro ponto de destaque para tal escolha metodológica foi a possibilidade da utilização de importantes instrumentos, bem como estudo de caso e trabalho em grupo no processo de ensino e aprendizagem.

Em vista de tais elementos, o objetivo deste relato é descrever o contexto e a execução das aulas práticas de "local de crime" oferecidos na disciplina de Odontologia Forense na Faculdade de Odontologia da Universidade de São Paulo (FO-USP).

\section{Descrição}

Após embasamento teórico (aula expositiva e leitura de uma apostila disponibilizada em ambiente virtual de aprendizagem - AVA), propõe-se uma dinâmica ativa na qual o local de um crime hipotético é montado. Em seguida, exige-se dos alunos a observação e a descrição precisa de tal espaço, bem como se demanda deles a recriação de um momento da história que ali se teria passado. Materializam-se os resultados por meio de um documento chamado de laudo pericial daquela localidade.

Com auxílio de objetos, materiais de interesse odontológico, roupas e réplicas de um esqueleto humano, introduz-se uma coleção de vestígios que variam a cada aula, tornando a dinâmica sempre renovável e interessante (Figuras 1 e 2). Isso faz com que o aluno desenvolva os princípios da Criminalística, quais sejam a observação, a análise, a interpretação, a descrição e a documentação de uma maneira prática ("aprender fazendo") (TOCCHETTO \& STUMVOLL, 2014).

As informações colhidas são descritas e registradas em formato de um minucioso laudo técnico

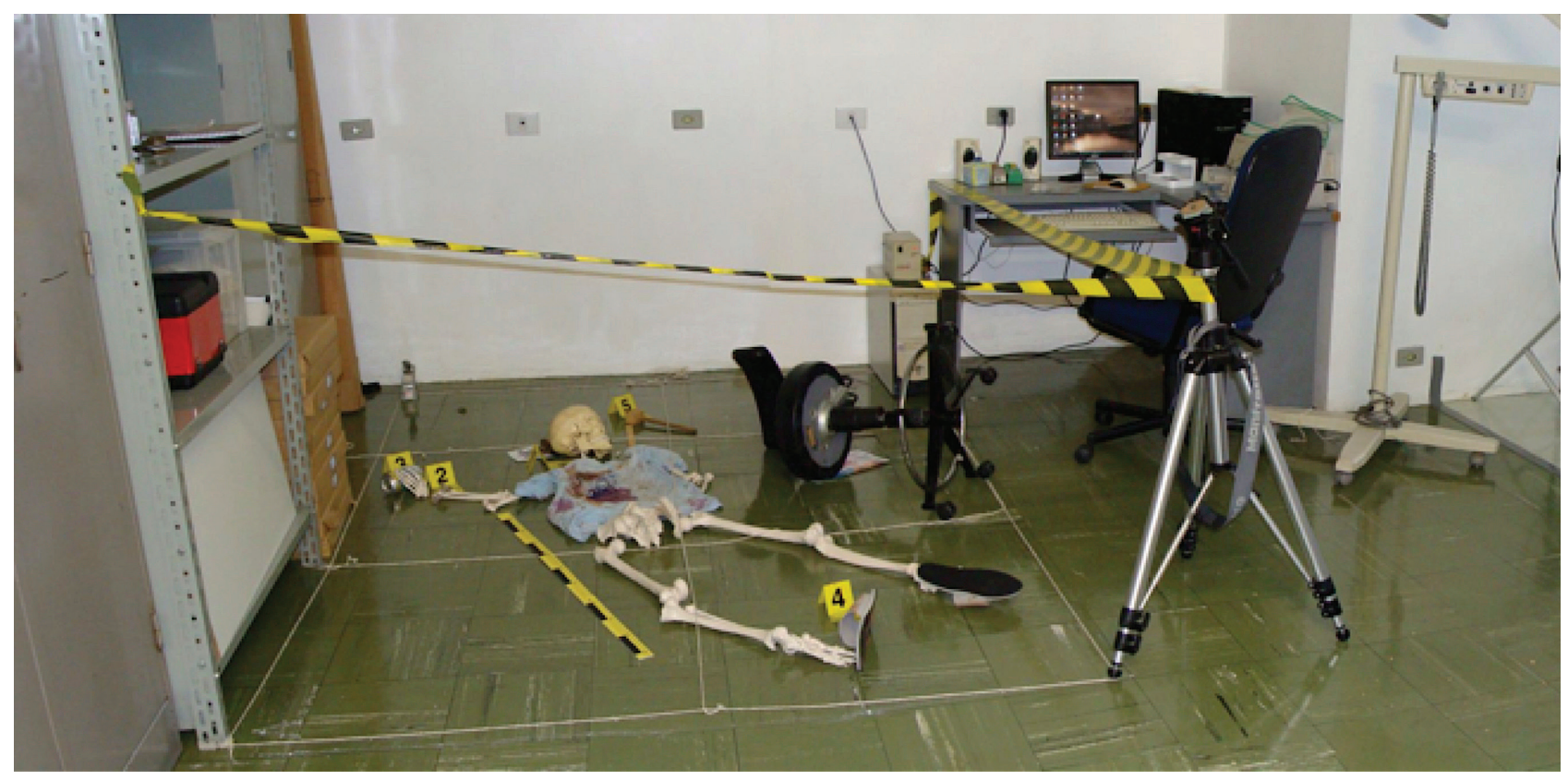

Figura 1 - Exemplo de local de crime hipotético com vestes, objetos odontológicos e material humano artificial, preparado para que os alunos possam exercitar a percepção de detalhes, a descrição precisa e a produção de um relatório técnico estruturado. 


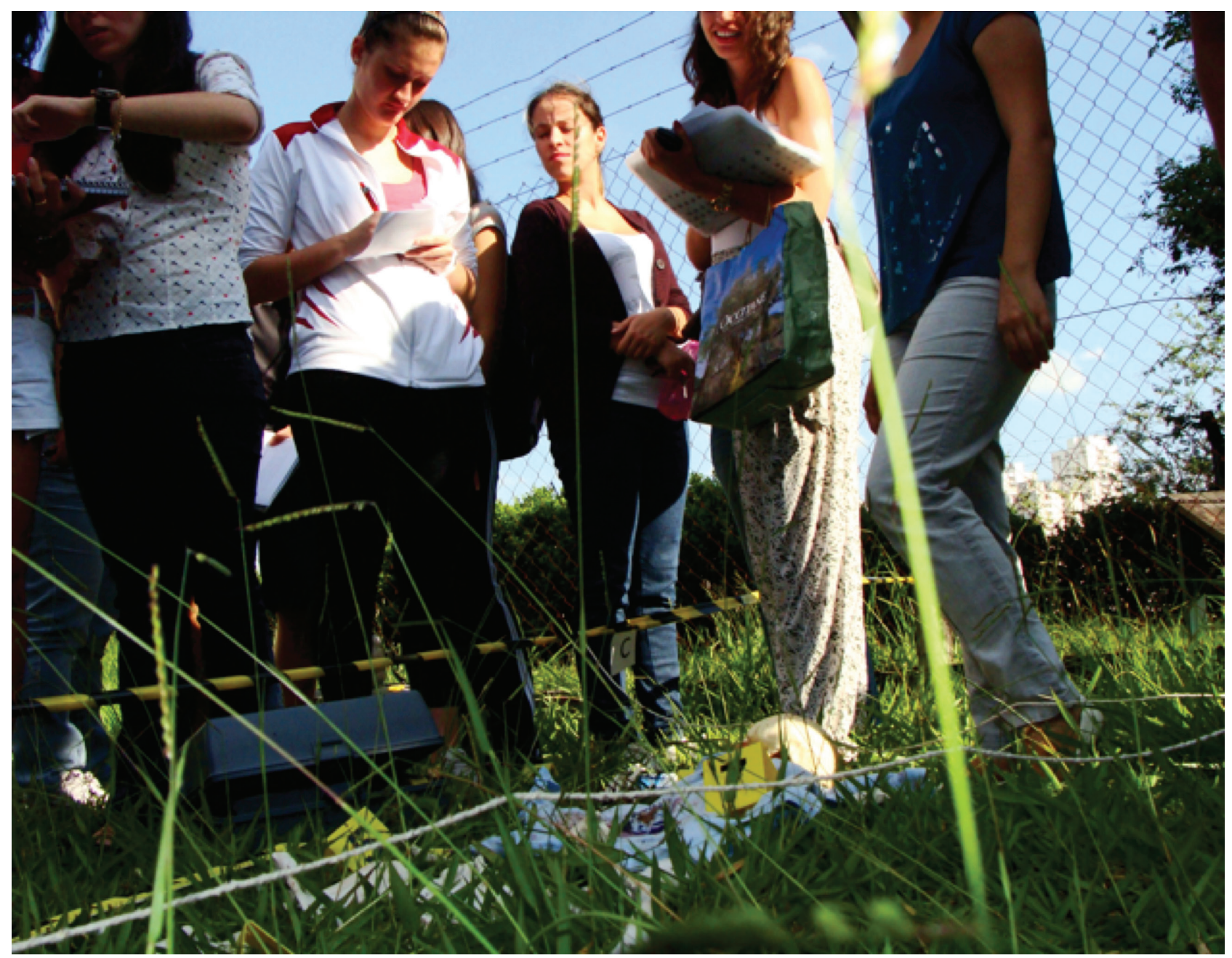

Figura 2 - Coleta de evidências e trabalho em equipe.

que dispõe da mesma estruturação utilizada em perícias oficiais. $\mathrm{O}$ documento é fornecido em um modelo a ser completado, favorecendo o entendimento dessa organização (Figura 3). Ou seja, por meio de um documento chamado de laudo pericial, aquele local é materializado. Como os alunos são divididos em grupos, há a necessidade de que sejam desempenhadas tarefas distintas - como a do descritor, que observa os detalhes e os relata para o transcritor. Cabe a este, por sua vez, preencher o laudo do "local do crime". O fotógrafo aplica as técnicas pertinentes, que foram abordadas em aulas anteriores. Por fim, o desenhista procura sintetizar as informações colhidas em uma representação esquemática, chamada de croqui. O trabalho em equipe desempenhado, além da construção de conhecimento em conjunto, exercita a liderança e a responsabilidade, o que é considerado vantajoso no contexto de trabalho mais marcadamente individual predominante na Odontologia.

Após a prática, cada grupo deve postar o laudo produzido no AVA para que todos os alunos tenham acesso ao documento, havendo, assim, uma construção mais ampla do conhecimento, pois uma equipe pode ver os laudos feitos pelas demais, o que favorece a troca de informações. Os professores, em sala de aula e/ou por meio do ambiente virtual de aprendizagem, dão o feedback dessa atividade aos grupos e discutem as dúvidas e sugestões apresentadas pela turma.

\section{Discussão e Conclusão}

A dinâmica proposta permite a realização de um exercício não só relevante para as ciências forenses, mas também para o cotidiano clínico do aluno de graduação e profissional da Odontologia. O pensamento pericial, a estruturação do laudo e as implica- 

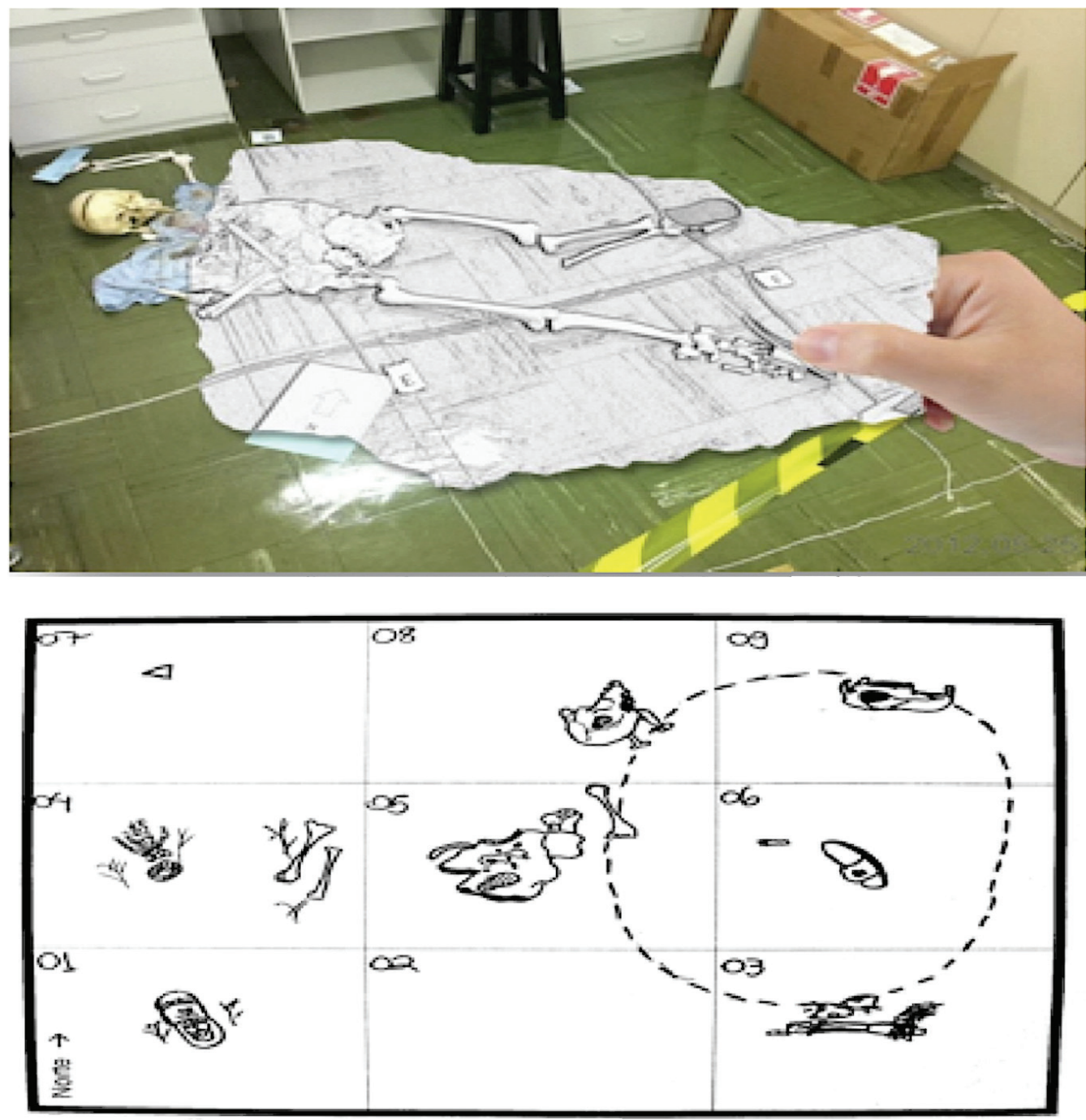

Figura 3 - Relato esquemático do local periciado.

ções legais envolvidas auxiliam na observação clínica diária, nas decisões, na comunicação com demais profissionais e no desenvolvimento de relatórios precisos que compõem o prontuário odontológico.

Outra característica importante e que norteia tal processo é a mobilização de conteúdos da disciplina de Odontologia Forense e de outras do currículo do curso de graduação para o desenvolvimento de uma conclusão lógica. Dessa maneira, referências anatômicas, observação dos materiais dentários, análise de características das próteses e restaurações, radiologia, dentre outros conteúdos, são, necessariamente, considerados no processo do desenvolvimento pericial. Isso torna o estudo multidisciplinar e estimula o aluno a buscar novos conhecimentos.

A disciplina também se vale de recursos tec- nológicos do AVA, o que ajuda na interação da classe, além de ser permitir o acompanhamento mais próximo do desenvolvimento do aluno pelo professor. Tal ferramenta é ainda capaz de evidenciar as dificuldades apresentadas pelo graduando que podem ser sanadas ao longo do processo de aprendizagem (MATTAR, 2013; SIEMENS, 2004; NOGI, 2005).

A dinâmica pedagógica aqui descrita tornou a aula de "local de crime" bastante lembrada na disciplina de Odontologia Forense, pois ela se destaca por apresentar conteúdo conexo com outras disciplinas e conhecimentos adquiridos ao longo do curso (Figura 4). Além disso, proporciona um meio de auxiliar o aluno a respeitar as diversidades e a trabalhar em equipe, fazendo-o confrontar opiniões e chegar a um consenso. 


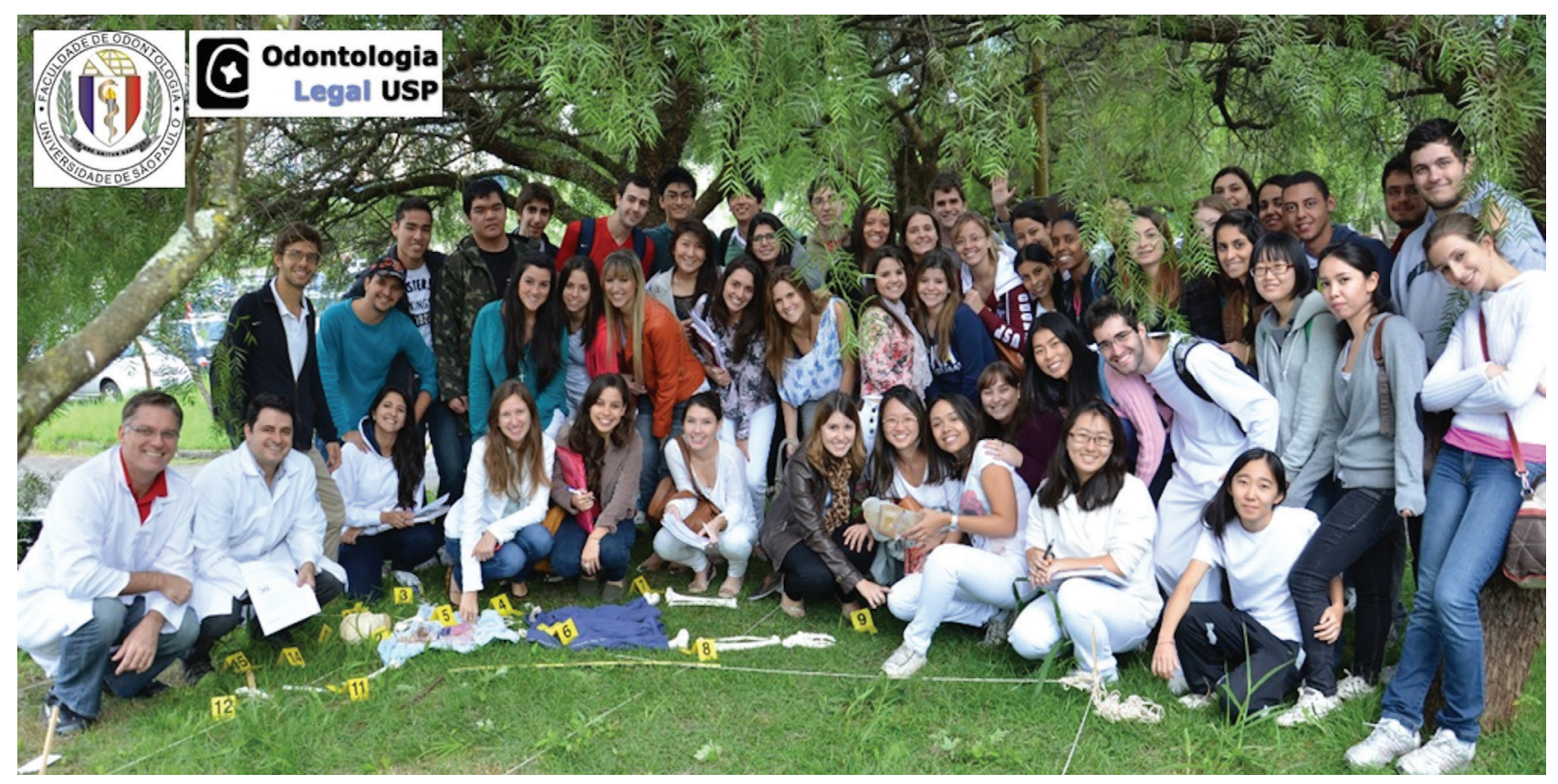

Figura 4 - Registro fotográfico de alunos que participaram da dinâmica de "local de crime".

\section{Agradecimentos}

Os autores gostariam de agradecer os professores e funcionários da faculdade de Odontologia USP, os alunos e pós-graduandos que ajudaram a realizar essa dinâmica nos últimos anos. Em especial Paulo Eduardo Miamoto Dias, Silvia V. Tedeschi-Oliveira, Mario M. Fernandes, Adriana Onesti, Natalie Haddad, Claudio Asano, Lara Herrera, Raíssa Strapasson.

\section{Referências Bibliográficas}

ANDRÉ, Marli E. D. A. "Estudo de Caso: Seu Potencial na Educação". Cadernos de Pesquisa, São Paulo, n. 49, maio 1984, pp. 51-54.

BARRON, Brigid. "Achieving Coordination in Collaborative Problem-Solving Groups". The fournal of the Learning Sciences, vol. 9, n. 4, 2000, pp. 403-436.

GOMES, Paulo de Tarso \& POZZEBON, Paulo Moacir Godoy. "Técnicas de Dinâmica de Grupo". In: CARVALHO, Maria Cecília Maringoni de (org.).
Construindo o Saber - Metodologia Científica: Fundamentos e Técnicas. $2^{\mathrm{a}}$ ed. Campinas: Papirus; 1989, pp. 129-135.

MATTAR, João. "Aprendizagem em Ambientes Virtuais: Teorias, Conectivismo e MOOCs". TECCOGS, n. 7, 2013, pp. 20-40.

NOGI, Fábio Massaharu. Internet como Ferramenta de Apoio Pedagógico no Processo de Ensino-Aprendizagem em Odontologia Legal. 133 p. Dissertação (Mestrado em Odontologia) - Faculdade de Odontologia, Universidade de São Paulo, 2005.

SCHUNK D. H. P. Learning Theories: An Educational Perspective. $6^{\mathrm{a}}$ ed. Boston: Pearson, 2011, pp. 229-280.

SIEMENS, George. "Conectivismo: Uma Teoria de Aprendizagem para a Idade Digital", 2004. Disponível em <https://www.academia.edu/7573922/CONECTIVISMO_Uma_Teoria_de_Aprendizagem_para_a_Idade_Digital $>$. Acessado em 22 jun. 2016.

TOCCHETTO, Domingos \& STUMVOLL, Victor Paulo. Criminalística. $6^{\text {a }}$ ed. Campinas: Millenium Editora, 2014. 
